\title{
THE BEETLE GENUS PARALIMULODES BRUCH IN NORTH AMERICA, WITH NOTES ON MORPHOLOGY AND BEHAVIOR (COLEOPTERA : LIMULODIDAE) ${ }^{1}$
}

By E. O. Wilson, T. Eisner, and B. D. Valentine Biological Laboratories, Harvard University

The family Limulodidae was erected by Seevers and Dybas in 1943 to receive the staphylinid subfamily Cephaloplectinae and the trichopterygid subfamily Limulodinae. It includes a small number of species with body form conspicuously modified for a myrmecophilous existence: body tear-shaped or oblong, head covered by the pronotum, base of the antennae protected by deep fossae, labrum in repose contiguous with the mentum, etc. These specializations are of the type generally characterizing "loricate synoeketes", ant guests more or less indifferently tolerated by their hosts and protected from occasional molestation by a shielded body form.

Of the five limulodid genera recognized by Seevers and Dybas, the most specialized and obscure is Paralimulodes Bruch. This genus has hitherto been known only from four specimens of the single species, $P$. wasmanni Bruch, taken with a colony of the army ant Neivamyrmex spegazzinii (Emery) at La Plata, Argentina in 1919. It was therefore a matter of some interest when the genus was recently rediscovered, this time in the southeastern United States. Living material was maintained with the host ant colonies in artificial nests long enough to record some aspects of behavior, and enough preserved material was obtained to fill in most of the important detail inadequately covered by Bruch's original description. New information obtained in this study is presented in the sections below.

Distribution and taxonomic status of the North American population. Over two hundred specimens, all apparently belonging to the same species, were collected by Wilson at the following three localities in central and northern

${ }^{1}$ Published with a grant from the Museum of Comparative Zoology at Harvard College. 
Alabama: Bryce Lake, Tuscaloosa, Tuscaloosa Co. [host Neivamyrmex carolinense (Emery)]; Hurricane Creek, near Peterson, Tuscaloosa Co. [host $N$. carolinense]; King Cove, Bankhead National Forest, Lawrence Co. [host $N$. nigrescens (Cresson)]. The species has been tentatively determined as $P$. wasmanni. Since syntypes of wasman$n i$ are not available at present, we have relied on Bruch's original description and detailed drawings. No difference could be found on this basis, and we feel confident in stating that the two populations must be very close if not

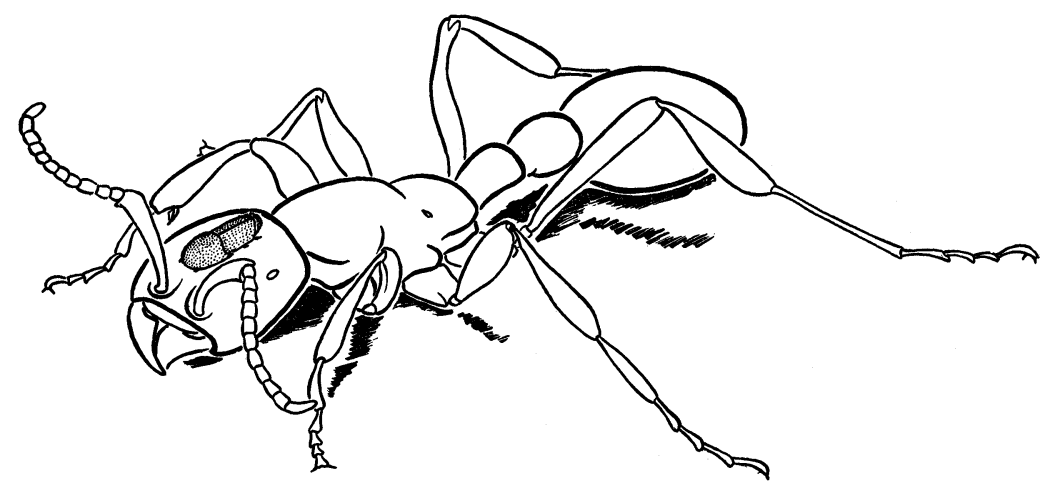

Text-figure 1. Paralimulodes riding on the head of a Neivamyrmex nigrescens major worker.

identical. Specimens have been deposited in the Museum of Comparative Zoology, Harvard University, and Chicago Natural History Museum.

Morphology. (See figures. Most of the specimens used in this study were cleared with $10 \% \mathrm{KOH}$ and stained with Chlorazol Black E, acid fuchsin, or fast green. Because of the minute size of the material, most of the examination was made under oil immersion lens.)

Size extremely small, total length approximately $0.6 \mathrm{~mm}$ Antenna 8-segmented. Antennal fossa deeply excavated but nevertheless capable of accommodating only the scape. The antenna is otherwise well protected, being able to move freely between the prosternum and the concave ventral surface of the remainder of the prothorax. The terminal four segments are flattened dorsoventrally. A pair of what seem to be sensory pegs, one dorsal and one ven- 
tral, project beyond the tip of the terminal segment. These are visible only under the best conditions of lighting and were apparently missed by Bruch.

Two "eye-spots", apparently nothing more than tiny optically light areas, are present near the outer lateral margins of the head. These are essentially no different from other such areas which occur sporadically on several other parts of the body (see pl. 13, fig. d), but may be significant in that they are larger and uniform in size and are evident at the same location in every specimen examined.

Maxilla tripartite; maxillary palp 4-segmented, the third segment greatly swollen and ovoid. The labium appears to be degenerate in comparison with that described by Seevers and Dybas for Cephaloplectus mus, although admittedly this structure could be seen only in ventral view in our material. Two segments are visible, the distal one subglobose and with no appendages other than the palps evident. Segmentation in the labial palps is apparently obsolescent.

The mandible consists of a well sclerotized piece, the distal portion of which is divided into a "molar" projection terminating in several sharp teeth, and a thin, nearly transparent "incisor area", edged by numerous seriate denticles barely within the limit of light resolution. The incisor area has never been described in other limulodid genera but may have been overlooked due to its almost invisible structure.

Paralimulodes does not differ much from Limulodes and Cephaloplectus in thoracic structure. Contrary to the claim of Bruch, the prosternum is not a distinct piece, but merges into the pronotum anteriorly by a pair of narrow arms. Posteriorly it is free and overlaps the mesosternum and anteromedian metasternal projection.

The tarsus is two-segmented, the basal segment sub-

\section{Explanation of Plate 12}

(Paralimulodes wasmanni Bruch; Lawrence Co., Ala.).-Fig. A, outline, dorsal view, showing habitus. Fig. B, dorsal view, with abdomen distended by treatment with $\mathrm{KOH}$. Fig. C, ventral view, abdomen also distended. (Sculptural detail not shown). 


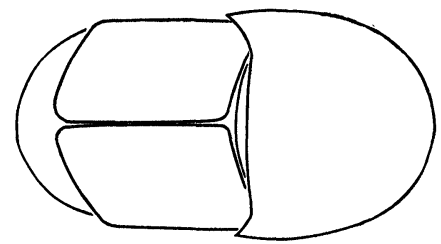

A
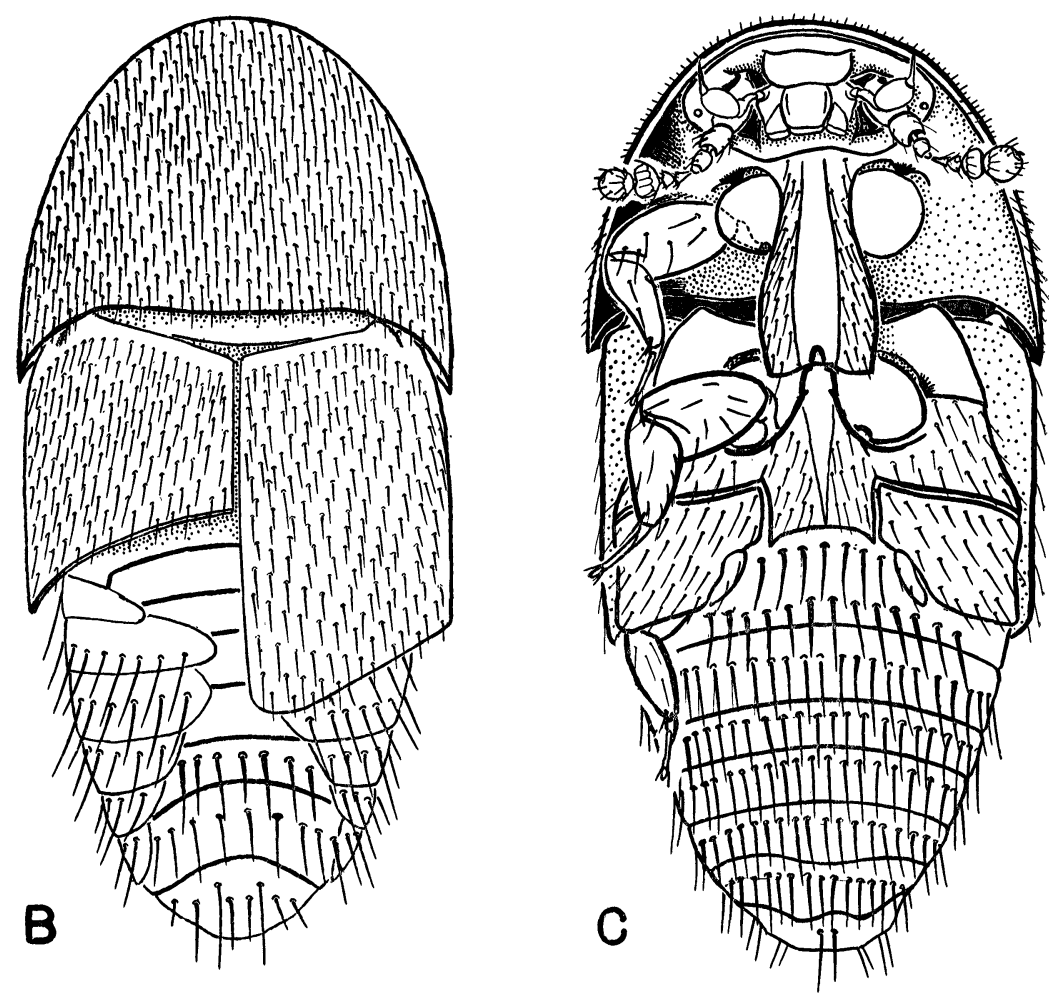

$0.2 \mathrm{~mm}$.

Wilson, Eisner and Valentine-Limulodidae 
triangular in outline and partly overlapping the cylindrical distal segment. The pretarsus contains some detail not resolvable by the light microscope, but there is visible a single (?) irregularly shaped, nearly transparent distal pad flanked by at least two bristles. Claws in the conventional sense are lacking.

Seven abdominal segments are visible in ventral view (see pl. 12, fig. B). Division in the anterior tergites is indistinct, so that correspondence with individual sternites is uncertain. Perhaps the most unusual feature of the abdomen is the shape of the first six visible sternites. These are very wide and are produced dorsally to overlap in part the adjacent tergites. The dorsal sternital tips are presumably what Seevers and Dybas refer to as "paratergites" in their general description of the limulodid abdomen. This peculiar modification in abdominal structure seems best interpreted as providing a sort of shingle-armor protection for the lateral intersegmental membranes.

Behavior. As noted previously, Paralimulodes occurs naturally with the army ants Neivamyrmex carolinense and $N$. nigrescens in Alabama. Both of these species are abundant within the presently known range of the beetle. That Paralimulodes is truly host-specific for Neivamyrmex is suggested by the following observations. A colony of $N$. nigrescens from Hurricane Creek, found within fifty feet of the infested carolinense colony, was maintained for several days with the queen in an artificial nest. No Paralimulodes could be found with the thousands of workers, despite the earlier proximity of the two ant colonies. But when beetles were isolated from the carolinense and placed in the nigrescens nest, they proceeded with little hesitation or opposition into the mass of resting workers. Twenty-four hours later they were still ensconced with their new hosts. When other Paralimulodes were transferred to

\footnotetext{
Explanation of Plate 13

(Paralimulodes wasmanni Bruch; Lawrence Co., Ala.). - Figs. a-d, mouthparts in ventral view. Fig. e, ventral view of left antenna. Fig. f, aedeagus tube, ventral view. Fig. g, spermatheca, ventral view. Fig. h, tarsus, including only structures clearly visible with the light microscope; terminal tarsal segment rotated to show pretarsus in dorsal view.
} 


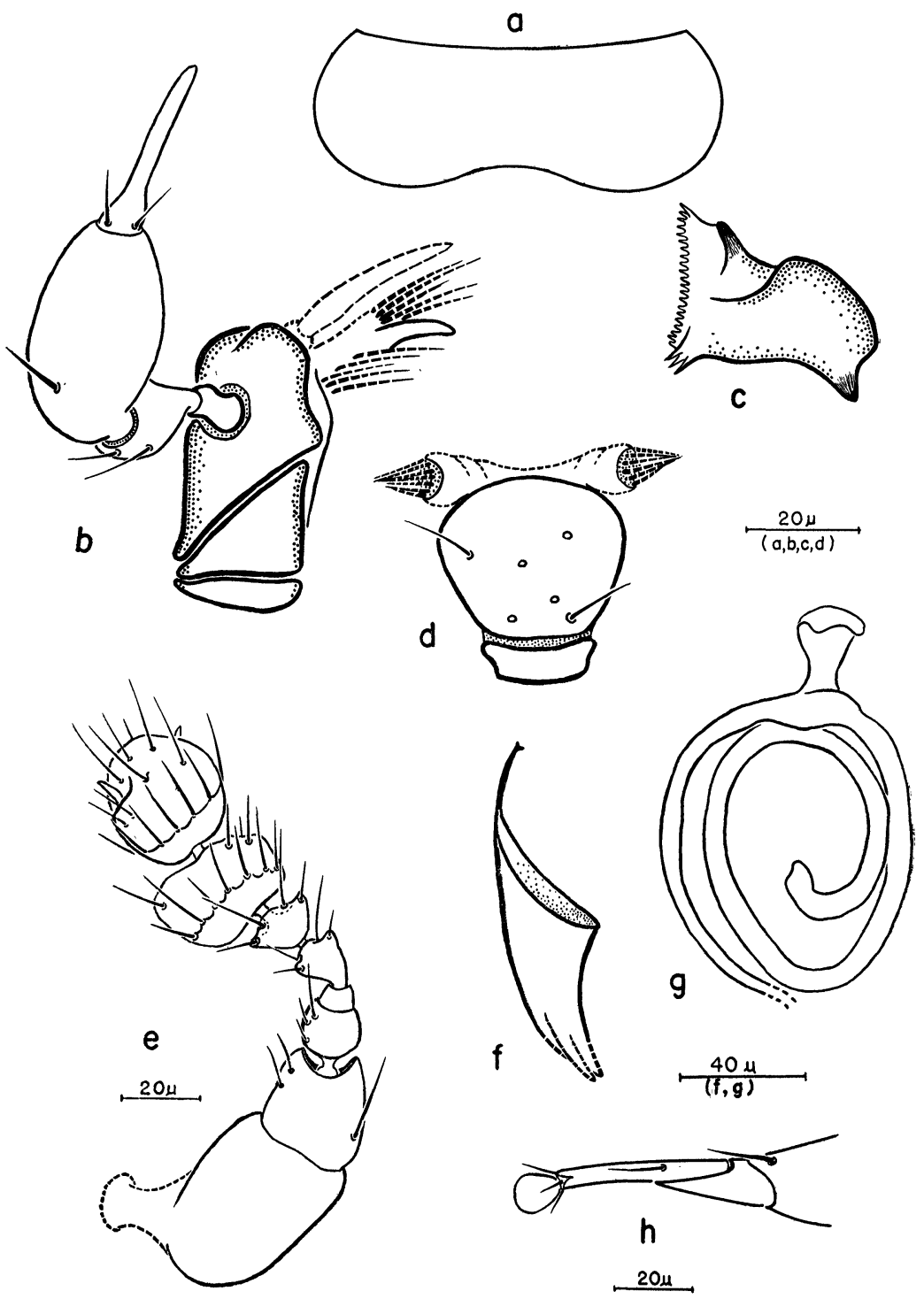

Wilson, Eisner and Valentine-Limulodidae 
nests containing colonies of the non-ecitonine species Monomorium minimum (Buckley), Crematogaster minutissima Mayr, and Camponotus pennsylvanicus (DeGeer), they completely ignored these ants and wandered aimlessly about the nest chambers.

The Paralimulodes present a very bizarre appearance in life. When resting they superficially resemble mites. They are usually to be seen riding on the heads and abdomens of the workers and only rarely run along the ground in a foraging column of the ants. On several occasions two were observed riding on the same worker and in this circumstance were positioned symmetrically on each side of the head or abdomen, a phenomenon already noted in some myrmecophilous mites (Wheeler, 1926) and in Limulodes (Park, 1933).

When the ants are moving in columns the beetles remain more or less stationary on single individuals. Only when the ants crowd together to rest do the beetles show much activity of their own. Then they begin to travel over the bodies of their hosts in light, rapid, jerky movements, climbing appendages, scurrying around curved body surfaces, and skipping freely from one individual to another. The ants do not seem to be bothered by this activity at all, and in fact show no sign that they are aware of their tiny guests' existence. Once a beetle was seen to cross the extended antennae of two workers which had met and were palpating one another, and even this impertinence failed to evoke a response.

Like Limulodes parki (see Park, 1933), Paralimulodes is a strigilator, obtaining its food by scraping organic matter from the cuticle of its hosts. On several occasions individuals were seen moving their mouthparts along the anterior gular rim and coxal insertions of resting workers. No ant brood was present in the nests at the time of observation, so that it could not be determined whether the beetles confine their attention to the adults.

Acknowledgement. The authors are indebted to Dr. H. S. Dybas for examining part of the Lawrence County series and making certain valuable corrections and suggestions relative to the foregoing section on morphology. 
1954] Wilson, Eisner, and Valentine-North American Paralimulodes 161

Literature Cited

PARK, 0 .

1933. Ecological study of the ptiliid myrmecocole, Limulodes paradoxus Matthews. Ann. Ent. Soc. Amer., 26: 255-261, fig.

Seevers, C. H. and H. S. Dybas

1943. A synopsis of the Limulodidae (Coleoptera): a new family proposed for myrmecophiles of the subfamilies Limulodinae (Ptiliidae) and Cephaloplectinae (Staphylinidae). Ann. Ent. Soc. Amer., 36: 546-586, 81 figs.

WHEELER, W. M.

1926. Ants, their structure, development, and behavior. Columbia Univ. Press. $663 \mathrm{pp}$. 

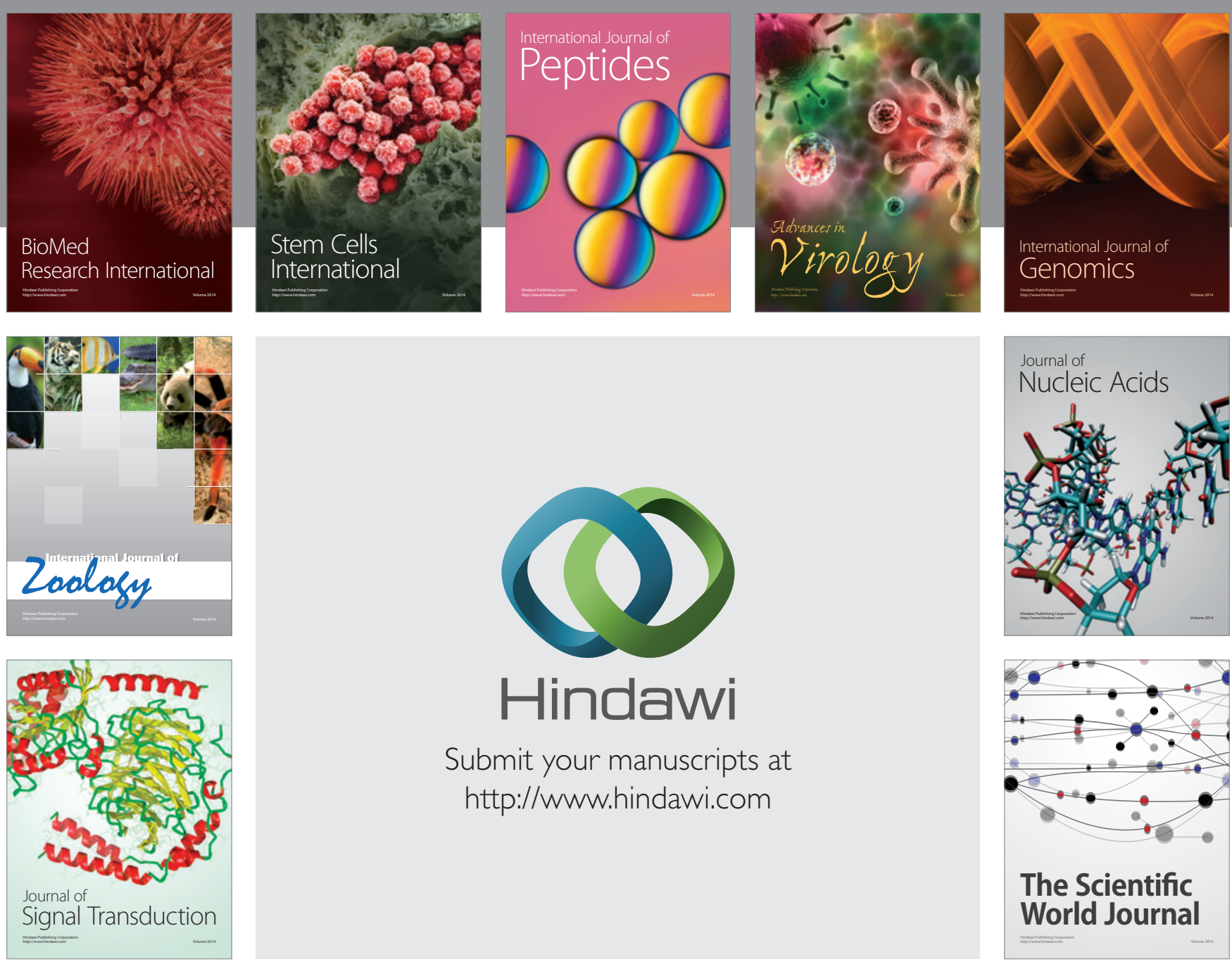

Submit your manuscripts at

http://www.hindawi.com
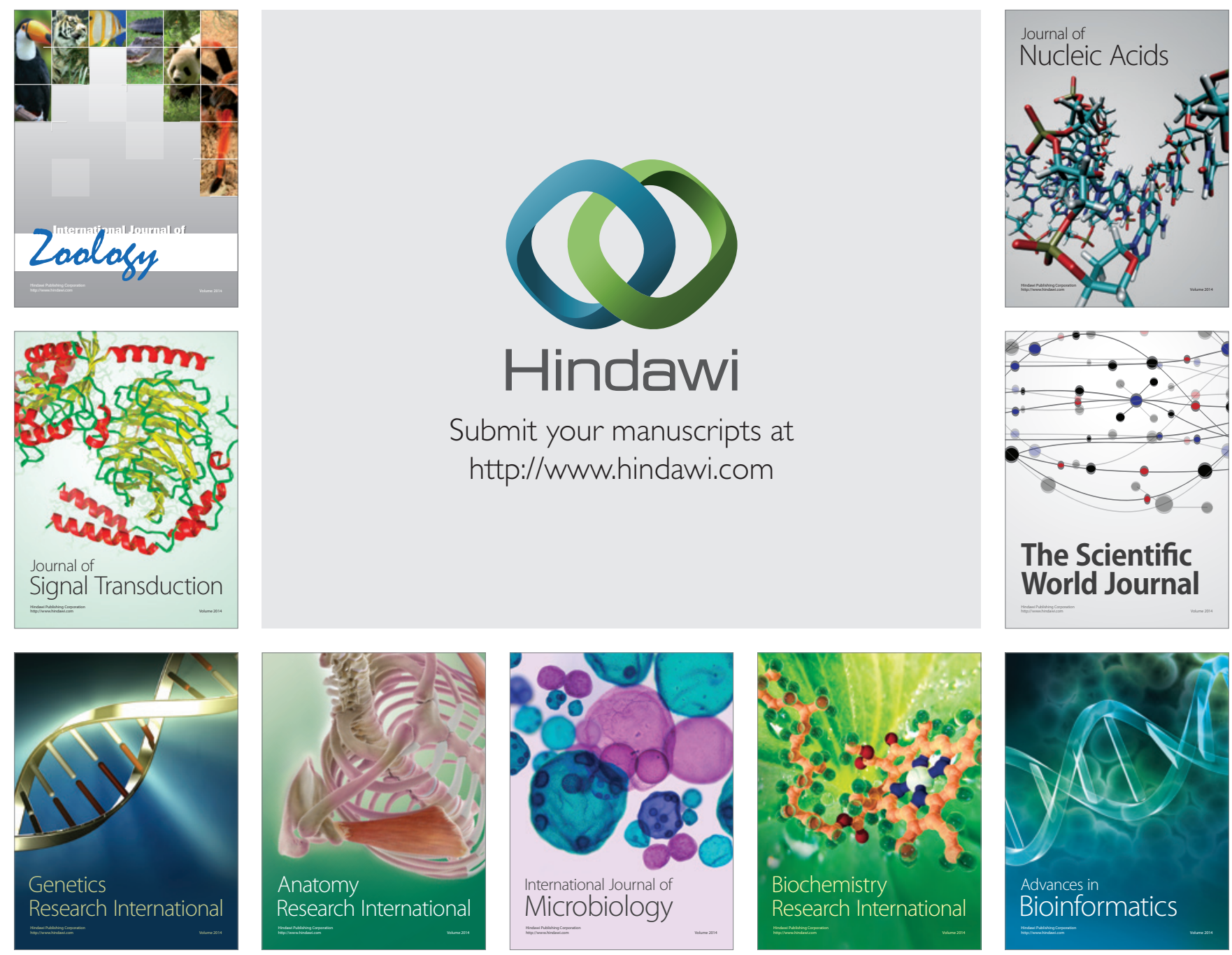

The Scientific World Journal
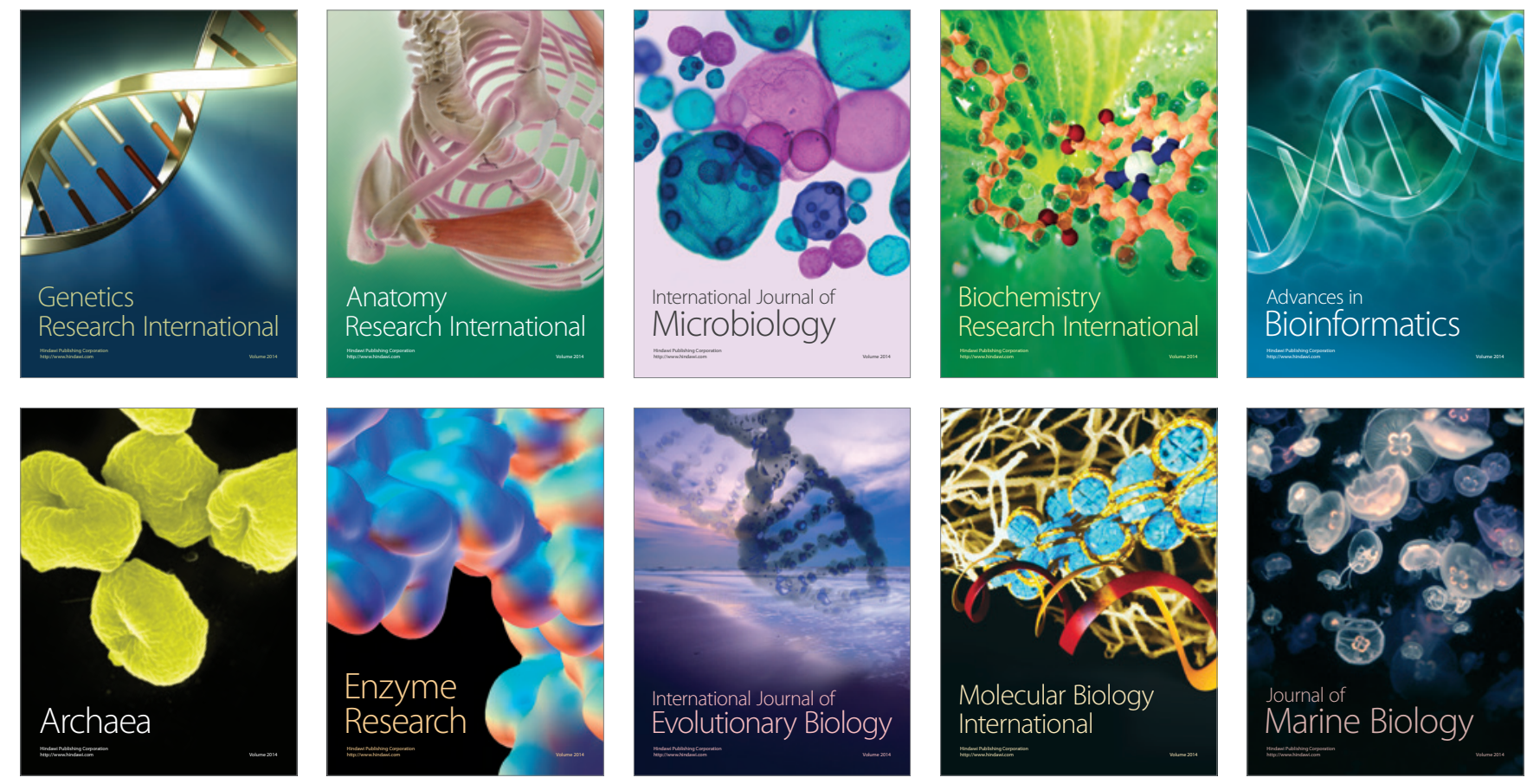